\title{
Analysis of Morphology of Normal Appendix using Contrast Enhanced CT Abdomen
}

\author{
Varun Narayan ${ }^{1}$, Sajin George Joseph ${ }^{2}$ \\ ${ }^{1}$ Assistant Professor, Department of Radiodiagnosis, ${ }^{2}$ Senior Resident, Department of Radiodiagnosis, Amala Institute of \\ Medical Sciences, Thrissur, Kerala, India \\ Corresponding author: Dr.Sajin George Joseph, Senior Resident, Department of Radiodiagnosis, Amala Institute of Medical \\ Sciences, Amala Nagar, Thrissur, Kerala, India
}

DOI: http://dx.doi.org/10.21276/ijcmsr.2019.4.3.9

How to cite this article: Varun Narayan, Sajin George Joseph. Analysis of morphology of normal appendix using contrast enhanced CT abdomen. International Journal of Contemporary Medicine Surgery and Radiology. 2019;4(3):C40-C43.

\section{A B S T R A C T}

Introduction: Appendix is identified as blind ending tubular structure arising from caecum and has variable intraluminal contents and position. Acute appendicitis is one of the common indications for emergency imaging studies.

Material and Methods: Contrast enhanced computed tomography images of abdomen from 120 patients without suspicion of acute appendicitis and without any pathology localized within right iliac fossa were examined retrospectively. The images were reviewed in axial,coronal and sagittal reformations for tracing appendix upto its tip; assessing intraluminal contents, maximum transverse diameter and single wall thickness of appendix. The relationship between appendicular diameter, intraluminal content and position with different age groups and gender were also determined.

Results: The mean diameter of the appendix was $6.87 \pm 1.73 \mathrm{~mm}$. Most common location of the tip of appendix was retrocecal position. Most of the appendices were opacified by enteric contrast. Mean single wall thickness of appendix was $1.99 \pm 0.9 \mathrm{~mm}$.

Conclusion: The understanding of variation in the diameter, wall thickness and position of the normal appendix will assist in enhancing the precision of diagnosis of appendix related pathologies, particularly appendicitis. Severe caution must be exercised in making a diagnosis of acute appendicitis solely considering diameter of appendix in the absence of other signs.

Keywords: Normal Appendix, CECT, Diameter, Luminal Contents, Location, Wall Thickness, Appendicitis

\section{INTRODUCTION}

Imaging has been widely used over the past two to three decades for evaluation and diagnosis of acute appendicitis which is the most common acute abdominal pathology in adults and children requiring surgery. ${ }^{1}$ Computed tomography (CT) is fast becoming the favored imaging modality for suspected acute appendicitis, especially in adults owing to its high sensitivity and specificity. ${ }^{2}$ Accuracy wise CT has the upper hand than ultrasound (US) as CT is less operator dependent. ${ }^{3}$ Also patient factors like obesity, overlying gas-filled bowel loops and differences in positions of appendix may pose serious challenges in visualizing normal as well as abnormal appendix with ultrasound. ${ }^{4,5}$ Patients undergoing laparoscopic appendicectomy also benefit from CT preoperatively. ${ }^{6}$

Another factor favoring CT is that normal appendix is more commonly visualized at CT thereby excluding the diagnosis of appendicitis for all practical purposes. ${ }^{7,8}$ The reported diameter of a normal appendix at CT is an extrapolation from US results ${ }^{5,9-11}$,with use of a $6 \mathrm{~mm}$ short-axis diameter as the upper limit of normal. ${ }^{7,8,12,13}$ However normal appendiceal diameter ranging from $6-11 \mathrm{~mm}$ in $\mathrm{CT}$ have been shown by recent studies. ${ }^{14}$ Using same diameter cut-off for ultrasound and CT for the diagnosis of appendicitis has been questioned by Orschelin and Trout. ${ }^{15}$

The purpose of this study was to determine the variability in CT characteristics of a normal appendix namely diameter, wall thickness, position and intraluminal contents.

\section{MATERIAL AND METHODS}

The study was conducted in the Department of Radiodiagnosis, Amala institute of medical sciences, Thrissur, Kerala.

The hospital picture archiving and communication system (PACS) was interrogated to identify all patients who underwent contrast enhanced CT examination of the abdomen with positive oral and rectal contrast, for various purposes retrospectively over the period starting from January 1 to May 31, 2019. Out of various indications, patients with pain in the right lower quadrant or a clinical suspicion of appendicitis and patients with history of appendicectomy were excluded.

The study included 120 patients, out of which 69 were males and 51 were females. Age of subjects ranged from 15 to 81 
years.

\section{Image Analysis}

The obtained axial images from picture archiving and communication system (PACS) were transferred to the work station (GE medical systems Milwaukee, USA) where the image analysis was performed by two experienced practicing radiologists.

Images were analyzed in axial, multiplanar reconstructions (MPR) and post processed maximum intensity projection (MIP) images. The appendix was visualized along its complete length and maximal outer diameter of the appendix was measured in a plane perpendicular to its axis using electronic calipers (Figure 1). Single wall thickness of the appendix was measured in walls in the same plane (Figure 2). All measurements were done to the nearest 0.1 $\mathrm{mm}$. In cases where the appendiceal lumen were collapsed (unopacified) the wall thickness was calculated as half of maximum diameter.

The density of the contents of the appendix was measured on axial images. We described it as opacified (hyperdense with $>80 \mathrm{HU})$, hypodense material $(<80 \mathrm{HU})$, air, partially opacified (Figure 3 ) and collapsed (unopacified).

The location of the tip of the appendix was described as paracolic- adjacent and along the ascending colon; retrocolic/ retrocaecal- behind the colon or caecum (Figure 4); pelvicextending to the pelvis; midline-extending to the midline. The mean and range of maximal diameter and single wall thickness of appendices were calculated from the data.

\section{RESULTS}

The appendix was visualized in all the 120 patients included. The mean maximal diameter was $6.87 \mathrm{~mm} \pm 1.73 \mathrm{~mm}(\mathrm{SD})$. The minimum caliber of appendix that we encountered was 3.6

\begin{tabular}{|l|c|c|}
\hline Position & Male (\%) & Female(\%) \\
\hline Midline & $7(10.1)$ & $3(5.9)$ \\
\hline Paracolic & $14(20.3)$ & $14(27.5)$ \\
\hline Pelvic & $18(26.1)$ & $20(39.2)$ \\
\hline Retrocecal/Retrocolic & $30(43.5)$ & $14(27.5)$ \\
\hline Grand Total Table-1: Location of appendix \\
\hline \multicolumn{2}{|c|}{} \\
\hline
\end{tabular}

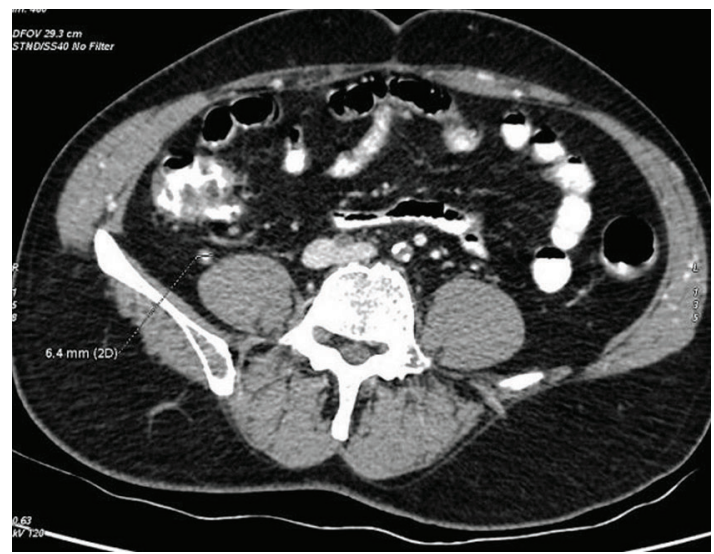

Figure-1: Measurement of appendicular maximal outer diameter in axial MPR image in the plane perpendicular to appendicular lumen. $\mathrm{mm}$ with a maximum of $13 \mathrm{~mm}$. The mean maximal diameter in males was $7 \pm 1.89$ (SD) $\mathrm{mm}$ and in females $6.7 \pm 1.46(\mathrm{SD})$ $\mathrm{mm}$. The mean single wall thickness of the normal appendix was $1.99 \mathrm{~mm} \pm 0.9 \mathrm{~mm}(\mathrm{SD})$ (range 0.5 to $5.3 \mathrm{~mm}$ ).

The most common location of the appendiceal tip was retrocolic or retrocaecal in 44 of 120 (37\%) appendices.

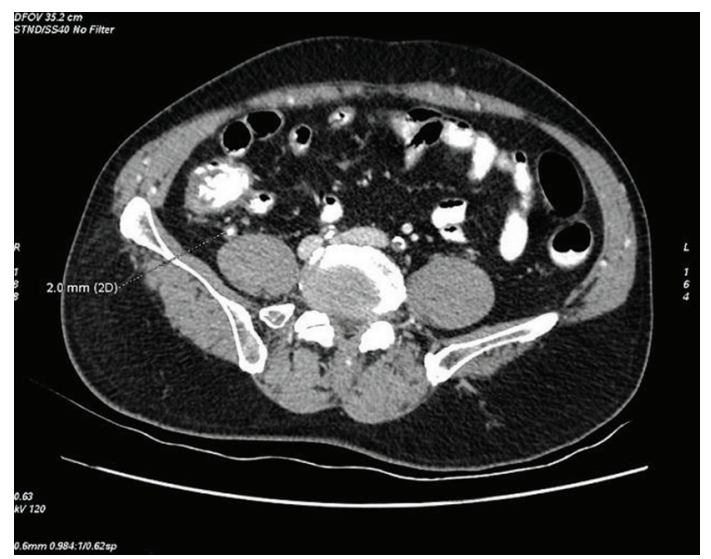

Figure-2: Measurement of appendicular single wall thickness in axial MPR image in the plane perpendicular to appendicular lumen.
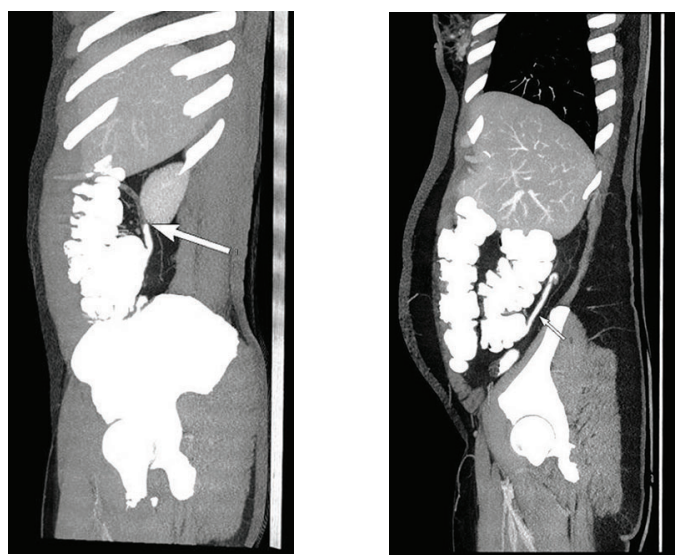

Figure-3: Sagittal MIP reformatted image showing partially opacified appendix (white arrow) with proximal part opacified by oral contrast and distal part having hypodense material; Figure-4: Sagittal MIP reformatted image showing retrocolic appendix(white arrow) which is completely opacified by oral contrast.

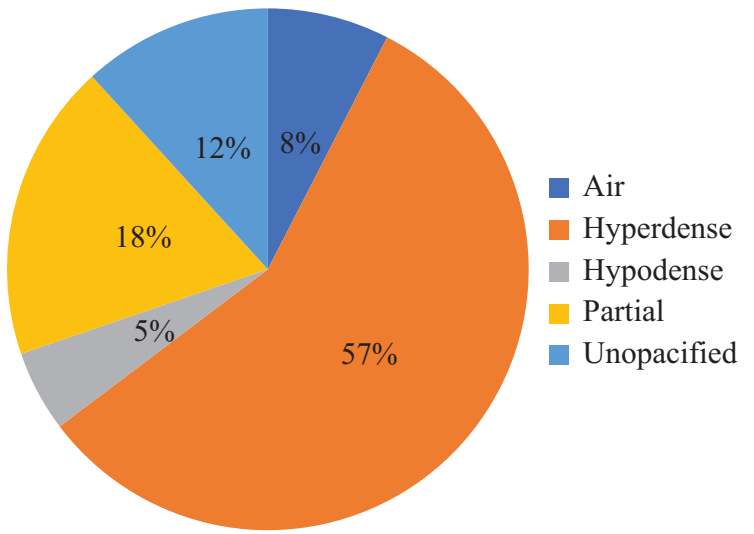

Figure-5: Pie chart showing distribution of appendix based on intraluminal contents. 
The appendiceal tip was pelvic in 38 (32\%), paracolic in 28 $(23 \%)$, and midline in 10 (8\%) (Table 1). In females the most common location was pelvic (20 out of 51) and in males retrocecal/retrocolic (30 out of 69 ).

The normal appendices contained hyperdense material (opacified) in 57\% (68 of 120), were partially opacified in $18 \%(22$ of 120$)$, completely air-filled in 8\% (10 of 120), collapsed (unopacified) in 12\%(14 of 120) and filled with hypodense material in 5\%(6 of 120) (Figure 5).

\section{DISCUSSION}

In our study appendix was visualized in all the patients. This is partly due to the fact that we included patients who underwent $\mathrm{CT}$ abdomen with intravenous and enteric positive contrast. It is in accordance with previous studies where administration of rectal or oral contrast provided the highest sensitivity ( $>90 \%$ ) for visualization of the normal appendix. ${ }^{3,8,16}$ However rectal contrast administration may be uncomfortable for the patients. In about $18 \%$ of individuals failure of rectal contrast to reach the caecum also has been noted..$^{17}$ Oral contrast may delay treatment as it takes 45 to two hours to reach caecum ${ }^{18,19,20}$ and may be poorly tolerated by patients with nausea and vomiting. In our study failure of appendix to be opacified by enteric contrast was seen in about 26\%(32 of 120) of patients. Moteki and Horikoshi in their study found high sensitivity and specificity (>80\%) for diagnosis of acute appendicitis for depth of the intraluminal appendiceal fluid greater than $2.6 \mathrm{~mm} .{ }^{21}$ They had found $3.4 \%$ of their normal population group showing this sign. In our study also we found only 5\%(6 out of 120$)$ patients showing appendix filled with hypodense material.

In our study the most common location of appendix tip is found to be retrocecal/retrocolic (44 of 120), second most common location was pelvic (38 out of 120). This is concordant with previous studies where they found tip of appendix most commonly located posteriorly to cecum. ${ }^{2,14}$ In our study, the mean maximal diameter was $6.87 \mathrm{~mm} \pm$ $1.73 \mathrm{~mm}(\mathrm{SD})$ (range, 3.6 to $13 \mathrm{~mm}$ ). Other studies have shown that the mean diameter of a normal appendix is $6-8 \mathrm{~mm} \cdot{ }^{20,22,23} \mathrm{~A}$ transverse diameter of up to $11 \mathrm{~mm}$ is reported in a normal appendix with air or contrast material distension. ${ }^{16,24,25}$ In our study, around 43\%of patients had an appendiceal diameter greater than $7 \mathrm{~mm}$. Other studies have proposed a threshold of $10 \mathrm{~mm}$ especially in cases where there is non visualization of luminal contents or there is no periappendiceal inflammatory signs. ${ }^{20,24,25}$ Our results are consistent with these studies and suggest that a diameter of $6 \mathrm{~mm}$ may not be a reliable cut off to predict appendicitis in the absence of other signs.

Mean single wall thickness in this study was 1.99 $\mathrm{mm} \pm 0.9 \mathrm{~mm}(\mathrm{SD})$. Other studies have shown mean wall thickness ranging from 1.2 to $2.22 \mathrm{~mm} .{ }^{14,20,26}$ Our findings are in accordance with these studies. The normal appendix has a reported maximum mural thickness less than $2-3 \mathrm{~mm} .{ }^{27}$ Previous reports showed that wall thickening beyond $3 \mathrm{~mm}$ may be considered a sign of inflammation and only $0.9 \%$ of normal appendices had a wall thickness of $3 \mathrm{~mm}$ or greater. ${ }^{14}$ However Willikens et al in their study had found wall thickness of more than $3 \mathrm{~mm}$ in $8 \%$ of patients. ${ }^{20}$ In our study wall thickness of more than $3 \mathrm{~mm}$ was found in $13 \%$ (16 of 120).

To the authors' best knowledge this is a first study of its kind evaluating the CT characteristics of normal appendix in Indian population. The study has its limitations, the major one being use of patient history as gold standard and absence of surgicopathological correlation for a normal appendix. However the inclusion of a patient with appendicitis in our patient population is considered highly unlikely since in their clinical course appendicectomy has not been performed or the diagnosis of appendicitis not suspected for atleast a month after the CT examination. We included only patients who underwent CT abdomen with intravenous and enteric contrast administration, excluding patients having history of appendicectomy. This would explain the difference in rates of visualization between our study and other previous studies. Inclusion of patients with enteric contrast also may have masked the visualization of appendicoliths which are usually hyperdense. However some previous studies have not found significance of appendicoliths alone to diagnose appendicitis ${ }^{21}$ and appendicoliths was found in $1.7 \%$ patients with normal appendix. ${ }^{20}$

\section{CONCLUSION}

Concluding we have found that diameter of normal appendix is variable and extrapolating ultrasound criteria for diagnosing appendicitis may not be an accurate approach in CT. MDCT with intravenous and enteric contrast is a formidable investigation to visualize and depict the anatomy of normal appendices. Various characteristics including wall thickness, intraluminal content should also be considered along with diameter to improve the accuracy of diagnosing pathologies related to appendix.

\section{REFERENCES}

1. Birnbaum BA, Wilson SR. Appendicitis at the millennium. Radiology 2000; 215(1):337-348

2. Ghiatas AA, Kritikos N. CT of appendicitis.In: Baert AL, Sartor K, Chapman AH,eds. Radiology and imaging of the colon.Berlin Heidelberg: SpringerVerlag. 2004;157-163.

3. Bursali A, Arac M, Oner YA, Celik H,Eksioglu S, Gumus T. Evaluation of the normal appendix at low -dose non-enhanced spiral CT. Diagn Interv Radiol 2005; 11 (3):45-50.

4. Akay HO, Akpinar E, Ozmen CA, Ergun O, Haliloglu M. Visualization of the normal appendix in children by non-contrast MDCT. Acta chirurgica Belgica. 2007;107(5):531-534.

5. Rioux M. Sonographic detection of the normal and abnormal appendix.American Journal of Roentgenology. 1992;158(4):773-778.

6. Ghiatas AA, Chopra S, Chintapalli KN. Computed tomography of the normal appendix and acute appendicitis. Eur Radiol1997; 7 (2):1043-1047.

7. Rao PM, Rhea JT, Novelline RA, et al. Helical CT technique for the diagnosis of appendicitis: prospective evaluation of a focused appendix CT examination. Radiology1997; 202 (6):139-144.

8. Rao PM, Rhea JT, Novelline RA, Mostafavi AA, 
Lawrason JN, McCabe CJ. Helical CT combined with contrast material administered only through the colon for imaging of suspected appendicitis. AJR Am J Roentgenol 1997; 169 (4):1275-1280.

9. Jeffrey RB Jr, Laing FC, Townsend RR. Acute appendicitis: sonographic criteria based on 250 cases. Radiology 1988; 167 (1):327-329.

10. Simonovsky V. Sonographic detection of normal and abnormal appendix. Clin Radiol 1999; 54:533-539.

11. Vignault F, Filiatrault D, Brandt ML, Garel L, Grignon A, Ouimet A. Acute appendicitis in children: evaluation withUS. Radiology 1990; 176 (3):501-504.

12. Stroman DL, Bayouth CV, Kuhn JA, et al.The role of computed tomography in the diagnosis of acute appendicitis. Am J Surg 1999; 178 (2):485-489.

13. Funaki B, Grosskreutz SR, Funaki CN. Using unenhanced helical CT with enteric contrast material for suspected appendicitis in patients treated at a community hospital. AJR Am J Roentgenol 1998; 171 (6):997-1001.

14. Tamburrini S, Brunetti A, Brown M, Sirlin CB, Casola G. CT appearance of the normal appendix in adults. European radiology.2005;15(10):2096-103.

15. Orscheln ES, Trout AT. Appendiceal diameter: CT versus sonographic measurements. Pediatric radiology. 2016;46(3):316-21.

16. Jan Y, Yang F, Huang J. Visualization Rate and Pattern of Normal Appendix on Multidetector Computed Tomography by Using Multiplanar Reformation Display. Journal of Computer Assisted Tomography. 2005;29(4):446-451.

17. Wise SW, Labuski MR, Kasales CJ, et al. Comparative assessment of CT and sonographic techniques for appendiceal imaging. AJR 2001; 176 (1):933 -941

18. Lee SL, Walsh AJ, Ho HS. Computed tomography and ultrasonography do not improve and may delay the diagnosis and treatment of acute appendicitis. Arch Surg 2001; 136 (6):556-562

19. Balthazar EJ, Rofsky NM, Zucker R. Appendicitis: the impact of computed tomography imaging on negative appendectomy and perforation rates. Am J Gastroenterol 1998; 93 (1):768-771

20. Willekens I, Peeters E, De Maeseneer M, de Mey J. The Normal Appendix on CT: Does Size Matter? PLoS ONE. 2014;9(5):e96476.

21. Moteki T, Horikoshi H. New CT Criterion for Acute Appendicitis: Maximum Depth of Intraluminal Appendiceal Fluid. American Journal of Roentgenology. 2007;188(5):1313-1319.

22. Keyzer C, Pargov S, Tack D, Créteur V, Bohy P, De Maertelaer $\mathrm{V}$ et al. Normal Appendix in Adults: Reproducibility of Detection with Unenhanced and Contrast-Enhanced MDCT. American Journal of Roentgenology. 2008;191(2):507-514.

23. Benjaminov O, Atri M, Hamilton P, Rappaport D. Frequency of Visualization and Thickness of Normal Appendix at Nonenhanced Helical CT. Radiology. 2002;225(2):400-406.

24. Grosskreutz S, Goff WB 2nd, Balsara Z, Burkhard TK. CT of the normal appendix. J Comput Assist Tomogr. 1991: 15 (1): 575-577
25. Lane MJ, Liu DM, Huynh MD, Jeffrey RB Jr, Mindelzun RE, et al. Suspected acute appendicitis: nonenhanced helical CT in 300 consecutive patients. Radiology 1999;213 (3):341-346

26. Webb E, Wang Z, Coakley F, Poder L, Westphalen $\mathrm{A}$, Yeh B. The equivocal appendix at CT: prevalence in a control population. Emergency Radiology. 2009;17(1):57-61

27. Dayal Y, DeLellis RA. Appendix. In: Contran RS, Kumar V, Robbins SL editors. Robbins Pathologic Basis of Disease. 4th ed. Philadelphia: Saunders; 1989, pp 902-4

\section{Source of Support: Nil; Conflict of Interest: None}

Submitted: 26-06-2019; Accepted: 17-07-2019; Published online: 24-07-2019 